\title{
RELATO DE EXPERIÊNCIA QUANTO A ORIENTAÇÃO DE CONDUTA FRENTE A ACIDENTES DE TRABALHO COM PÉRFURO-CORTANTES E FLUIDOS ORGÂNICOS*
}

\author{
Jacqueline Vieira de Sousa ${ }^{1}$, Luciana de Freitas Campos $^{2}$
}

\begin{abstract}
RESUMO: Trata-se de um relato de experiência sobre a orientação para a equipe de enfermagem acerca da conduta em caso de acidentes com pérfuro-cortantes e fluidos orgânicos durante o Estágio Supervisionado II: Área Hospitalar, em uma unidade de internação cirúrgica de um hospital de grande porte do estado de Minas Gerais, de março a junho de 2007, com auxiliares, técnicos e enfermeiros. Foi desenvolvido um diagnóstico situacional durante o Estágio que resultou na elaboração de um folder contendo informações sobre a conduta em casos de acidentes de trabalho com pérfuro-cortantes e fluidos orgânicos e a divulgação das informações nele contidas por meio de atividade de educação em serviço. A atividade desenvolvida promoveu a reflexão do profissional de enfermagem sobre a importância da prevenção, notificação e compreensão das fases percorridas pelo profissional acidentado.
\end{abstract}

PALAVRAS-CHAVE: Acidentes de trabalho; Educação em saúde; Equipe de enfermagem.

\section{EXPERIENCE ACCOUNT ON THE BEHAVIORADOPTED TO FACE OCCUPATIOAL ACCIDENTS INVOLVING SHARP OBJECTS AND BODY FLUIDS}

\begin{abstract}
This is an experience account on directions for the nursing team's behavior in case of accidents by sharp objects and body fluids during the Supervised Training Course II: Hospital Area, in a hospital in-patient unit of a big hospital in Minas Gerais State/Brazil, from March to June 2007, with aides, technicians and nurses. A situational diagnosis was developed during Training Course that resulted in the elaboration of a folder containing information on the procedures to be followed in case of occupational accidents by sharp objects and body fluids, and dissemination of the information contained in it through in-service education. The developed activity promoted nurses' reflection on the importance of prevention, reporting and understanding of the stages covered by the injured professional.
\end{abstract}

KEYWORDS: Occupational accidents; Health education; Nursing team.

\section{RELATO DE EXPERIENCIAACERCADE ORIENTACIÓN DE CONDUTADELANTE DE ACCIDENTES DE TRABAJO CON PERFORANTES CORTANTES Y FLUIDOS ORGÁNICOS}

RESUMEN: Relato de experiencia sobre dirección para el equipo de enfermería acerca de la conducta en casos de accidentes con perforación de corte y fluidos orgánicos durante las prácticas supervisadas II: Zona Hospitalar, en unidad de un gran hospital de estado de Minas Gerais, de marzo a junio de 2007, con el grupo de enferería. El diagnóstico fue elaborado mientras la etapa situacional que resultó en el desarrollo de um folder que contiene información acerca de la conducta en casos de accidentes en el trabajo con la perforación de corte y los fluidos y difusión de la informaciones en él contenidas a través de la actividad en el servicio de educación. La actividad desarrollada promovió la reflexión sobre la importancia de la prevención, apuntes y comprensión de las etapas percorridas por el profissional que sufre accidente.

PALABRAS CLAVE: Accidentes de trabajo; Educación en salud; Grupo de enfermería.

\footnotetext{
*Artigo extraído do Trabalho de Conclusão de Disciplina Estágio Supervisionado II: Área Hospitalar do Curso de Enfermagem da Universidade Federal dos Vales do Jequitinhonha e Mucuri-UFVJM.

${ }^{1}$ Discente. Curso de Graduação em Enfermagem da UFVJM.

${ }^{2}$ Mestre. Docente. Curso de Graduação Enfermagem-UFVJM.
}

Autor correspondente:

Jacqueline Vieira de Sousa

Rua Roberto Carlos Rodrigues, 84 - 35701-000 - Sete Lagoas-MG

E-mail: jacque7vieira@hotmail.com.

Recebido: 15/04/08

Aprovado: 13/10/08

Cogitare Enferm 2008 Out/Dez; 13(4):602-6 


\section{INTRODUÇÃO}

A vulnerabilidade do profissional de saúde, da exposição a vários agentes biológicos predispõe a risco de infecção por patógenos ${ }^{(1)}$. A maioria das contaminações está relacionada a acidentes com pérfuro-cortantes e fluidos orgânicos, destacando o sangue. Os agentes infecciosos mais relevantes na aquisição de infecções por via sanguínea são os vírus da Hepatite B (HBV), Hepatite C (HCV) e o Vírus da Imunodeficiência Humana (HIV) ${ }^{(2)}$.

Com o aparecimento da Síndrome da Imunodeficiência Adquirida (SIDA), em 1987, o Centers for Disease Control and Prevention (CDC) elaborou um guia com recomendações sobre precauções com fluidos orgânicos a todos os profissionais de saúde. Em 1994, o CDC e o Hospital Infection Control Practices Advisory Committee, reformularam o guia para isolamento e precauções em isolamento em hospitais, passando a recomendar as precauções padrões (PP) $)^{(2)}$. Com o intuito de prevenir acidentes ocupacionais, as PP propõem que os profissionais de saúde, ao manipular agulhas não as reencapem ou dobrem e que sejam desprezadas juntamente com outros materiais pérfurocortantes em recipientes próprios (coletores). As PP também estabelecem a necessidade do uso de Equipamentos de Proteção Individual (EPIs) como avental, óculos, luvas e enfatizam a lavagem das mãos ${ }^{(2)}$.

No Estado de São Paulo, das notificações de acidentes com Material Biológico em profissionais de saúde, 86\% envolveram exposição percutânea e 82\% sangue. A maioria dos acidentes estava relacionada à equipe de enfermagem (58\%), seguido de funcionários da limpeza $(8,36)$ e médicos $(7,0 \%)^{(3)}$.

As conseqüências da exposição ocupacional aos patógenos veiculados pelo sangue ou outros fluidos corpóreos podem levar a manifestação de doenças tendo repercussões na saúde mental do profissional e familiares, bem como a mudanças de hábitos sexuais, alteração do relacionamento social e familiar e exposição aos efeitos das drogas profiláticas ${ }^{(4)}$.

Outro fato relevante, é que o Brasil ainda enfrenta o problema da subnotificação dos acidentes de trabalho na área da saúde, dificultando a análise da real situação. Estudos apontam que a subnotificação está relacionada a desinformação em relação aos riscos e aos aspectos epidemiológicos e jurídicos que envolvem o acidente, a submissão dos trabalhadores às condições impostas pelos serviços relacionados à falta de tempo para notificação e ao medo de perder o emprego, principalmente no setor privado ${ }^{(5)}$. A subnotificação pode relacionar-se, também, a valoração da importância dada ao registro da Comunicação de Acidentes de Trabalho dada pelos profissionais responsáveis por essa atividade, os quais privilegiam o comprimento de normas burocráticas, mas não o envolvimento profissional com a questão do acidentado, fazendo com que este fique desmotivado a notificar o acidente ${ }^{(4)}$.

Um dos desafios da enfermagem consiste em consolidar a prevenção, também, no ambiente de trabalho desenvolvendo ações educativas que minimizem a exposição a riscos de acidentes, atuando como profissionais comprometidos com a melhoria da saúde e o direito ao trabalho com dignidade e segurança para todos ${ }^{(6)}$, o que implica em um envolvimento diferenciado com relação ao processo de trabalho em saúde pois envolve questões de relacionamento humano no trabalho.

Diante do exposto, fazemos saber que aspectos relacionados a risco de exposição a patógenos por acidentes com pérfuro-cortante e fluidos orgânicos e a subnotificação de acidente de trabalho foi empiricamente observados durante a Disciplina Estágio Supervisionado II-Área Hospitalar de uma Instituição de Ensino Superior pública. Esta disciplina é oferecida no $8^{\circ}$ semestre do Curso de Graduação em Enfermagem tendo por objetivos desenvolver a assistência direta e indireta, embasada em conhecimento científico, em conformidade com o Código de Ética de Enfermagem e com os regimentos da universidade e do hospital estagiado; planejar, executar e avaliar a assistência de enfermagem com vista a promover a saúde do trabalhador; planejar e executar ações de educação em saúde, individual ou em grupo, aos integrantes do serviço de saúde, dentre outras.

Este estágio tem 450 horas aula e acontece em um hospital geral de grande porte do estado de Minas Gerais, de segunda a sexta-feira, 6 horas por dia, totalizando 30 horas semanais. Os alunos são distribuídos nas unidades por meio de sorteio e desenvolvem suas atividades sob orientação do enfermeiro da unidade e sob supervisão dos professores da disciplina, que visitam os setores diariamente e procedem a avaliação e orientações necessárias para o andamento do estágio.

Assim, este artigo tem por objetivo relatar a experiência vivenciada sobre a orientação para a equipe de enfermagem acerca da conduta em caso de acidentes com pérfuro-cortantes e fluidos orgânicos. 


\section{RELATO DA ATIVIDADE}

Durante o Estágio Supervisionado II: Área Hospitalar foi solicitado como atividade de conclusão desta disciplina a realização de um diagnóstico situacional com o intuito de identificar uma dificuldade enfrentada no setor no qual o acadêmico estivesse lotado, cuja resolução do problema fosse exeqüível. Da observação empírica da prática identificaram-se a manipulação significativa de materiais pérfurocortantes e fluidos orgânicos pelos profissionais de enfermagem da unidade estagiada, expondo-os constantemente a riscos de acidentes. As conseqüências de possíveis acidentes prejudicam o profissional (aspecto físico, psíquico, espiritual e financeiro), o paciente (prejuízo na assistência prestada por desatenção do funcionário ou diminuição do número deste para prestar a assistência) e a instituição (diminuição do número de funcionários, aumento de gastos e déficit da qualidade da assistência).

Em conversa informal com a equipe de enfermagem, causou-nos inquietação a informação de que profissionais teriam se acidentado no trabalho durante sua vida profissional e que não abriram a CAT e que desconheciam a conduta a ser tomada em caso de acidentes de trabalho envolvendo pérfuro-cortantes e fluidos orgânicos.

A Unidade de Internação estagiada é a de Clínica Cirúrgica de um hospital geral público de grande porte do estado de Minas Gerais, que contém 30 leitos para atendimento de pacientes adultos em situação de atendimento de pré e pós-operatório. Conta com uma equipe de enfermagem composta por enfermeiros, técnicos e auxiliares. A carga horária trabalhada é de 6 horas pela manhã, 6 horas no turno da tarde e no período noturno 12 horas, perfazendo 30 horas semanais.

Uma das características do processo de trabalho em clínica cirúrgica consiste na realização de procedimentos invasivos e conseqüente contato com secreções orgânicas, o que pode favorecer o contato com microorganismos patogênicos que, em caso de acidente de trabalho, pode levar ao desenvolvimento de doença e trazer prejuízos para o profissional, para o paciente e para a própria instituição.

Para a realização do diagnóstico situacional houve ampla discussão entre discente, docente e enfermeiros do setor e consensualmente foi estabelecido que o problema a ser trabalhado estaria relacionado a conduta em caso de acidentes de trabalho com pérfurocortantes e fluidos orgânicos. Faz-se saber que o período para o seu desenvolvimento foi de março a junho de 2007, totalizando 75 dias, sendo uma das atividades propostas no plano de curso da disciplina.

Então se buscou informações se o hospital possuía protocolo referente a temática junto ao Departamento de Medicina e Segurança do Trabalho, na Comissão de Controle de Infecção Hospitalar(CCIH) e ao Departamento de Recursos Humanos, sendo que o hospital oferece atendimento a profissionais vítimas de acidente de trabalho mas referiram que existe subnotificação. Foi apresentada aos trabalhadores destes setores a idéia do desenvolvimento de um folder contendo condutas em caso de acidentes com pérfurocortantes e fluidos orgânicos como diagnóstico situacional sendo que a CCIH forneceu as folhas de papel sulfite e disponibilizaram computador e impressora para a confecção do mesmo.

O folder foi elaborado contendo informações sobre a conduta de encaminhamento em caso de acidentes com pérfuro-cortantes e fluidos orgânicos, baseadas em literatura ${ }^{(1,6,8)}$ e discussão com as enfermeiras da unidade e docentes da disciplina. As informações foram subdividas em conduta imediata após acidente e conduta conforme sorologia do paciente-fonte, considerando a exposição ao vírus da imunodeficiência adquirida e das hepatites B e C.

Quanto as condutas imediatas após acidentes destaca-se que em pele íntegra deve-se lavar o local com água e sabão por 5 minutos, secar e aplicar álcool a $70 \%$. Em situação de pele lesada por dermatite, ferimento prévio e lesão perfurante, lavar a região com água e sabão por 5 minutos e não aplicar anti-sépticos. Em lesão cortante recomenda-se lavar com solução isotônica e, caso haja necessidade de sutura, esta fica a critério da avaliação e conduta médica. Em caso de exposição da mucosa ocular, lavar com solução isotônica durante 5 minutos. Em mucosa oral, lavar com água, bochechando e desprezando por 5 minutos.

Após cuidados imediatos deve-se procurar o médico do Serviço de Atendimento a Saúde do Trabalhador ou a Comissão de Controle de Infecção Hospitalar, que prestará o primeiro atendimento, solicitará sorologia da fonte e notificação do caso através do CAT.

Quando a fonte for desconhecida, realizar o exame de sangue do profissional acidentado para o HIV, HBV e HCV. Solicitar exames para o pacientefonte, realizando teste rápido para o HIV, antígeno de superfície do vírus da hepatite B (HbsAg) e anti-HCV. A solicitação dos exames é feita após informar o 
paciente-fonte a natureza e importância dos testes. Paciente bem orientado não recusa a fazer sorologia.

A conduta conforme sorologia do paciente consiste na não necessidade de nova sorologia quando paciente for positivo para HIV e doente crônico de hepatite $\mathrm{C}$ ou $\mathrm{B}$; paciente com sorologia documentada e negativa deve-se avaliar necessidade de nova sorologia; paciente-fonte negativo para HIV, encerrar o caso para HIV e o paciente-fonte positivo para HIV requer os cuidados: 1 . Determinar o material biológico e tipo (mucosa, pele integra e percutânea) de exposição, para assim determinar a profilaxia. 2. A quimioprofilaxia compreende esquema básico com Retrovir por 28 dias e esquema completo com Retrovir, Epivir e Indinavir por 28 dias, conforme prescrição médica. 3. É aconselhado usar mais de um anti-retroviral, devido à resistência viral. 4. Em intervalos de seis semanas, três meses e seis meses é solicitado novo anti-HIV.

Ressalta-se que nos Estados Unidos há relatos de casos de funcionários que se acidentaram e usaram 3 retrovirais e contaminaram-se.

Quando o paciente-fonte HCV positivo solicitar do profissional o teste anti-HCV. Se o profissional acidentado for anti-HCV negativo, repetir anti-HCV e transaminases em seis meses. Profissional acidentado anti-HCV positivo, encaminhar para acompanhamento ambulatorial. Ressalta-se que não há vacina para profilaxia para hepatite $\mathrm{C}$ e a precaução é o único meio de reduzir a contaminação.

Em paciente-fonte HBV positivo e profissional não vacinado para hepatite $\mathrm{B}$, iniciar vacinação para hepatite B, administrar imunoglobulina e realizar acompanhamento sorológico. Para profissional vacinado para hepatite B, não- responsivo deve-se administrar imunoglobulina e proceder a acompanhamento sorológico. Já para profissional vacinado para hepatite B, responsivo, não imunizar e não há necessidade de acompanhamento com testes sorológicos.

Uma vez concluído o folder foi pensado na estratégia de educação em serviço que versasse sobre a prevenção da exposição ao risco de acidente de trabalho por pérfuro-cortantes e fluidos orgânicos, utilizando-se desse momento também para divulgação do conteúdo do referido folder.

A educação em serviço ocorreu no período da tarde por ser o horário estagiado. Para divulgação do material foi utilizada, ainda, a passagem de plantão e, neste momento, os profissionais receberam o folder e dúvidas eram sanadas, se necessário. Outra estratégia foi deixar fixado no mural informativo da unidade, bem como no manual de normas e rotinas da unidade.

Durante a aula expositiva dialogada apareceram aspectos como a exposição a patógenos por manuseio inadequado de pérfuro-cortantes, causando lesão percutânea, em especial relacionado a agulha, comentário que veio ao encontro da literatura ${ }^{(3)}$ onde no Estado de São Paulo 86\% de trabalhadores da saúde apresentaram exposição percutânea, $82 \%$ foi relacionado a sangue e 58\% eram profissionais de enfermagem. Neste contexto, faz-se necessário e importante intensificar ações para que se minimize a manifestação desse comportamento na equipe de enfermagem e que trabalhar com as questões envolvendo pérfuro-cortantes e fluidos orgânicos ainda é um desafio na prática da enfermagem.

As estratégias de divulgação do folder permitiram que a equipe de enfermagem intensificasse a discussão sobre esta temática. Em caso de dúvidas e sugestões, estes trabalhadores procuraram pela discente e pelos enfermeiros para falar sobre o tema. Ainda, houve repercussão e outros profissionais de saúde procuraram os enfermeiros buscando informações.

Um aspecto importante de ser ressaltado é que a atividade de educação em serviço requer disponibilidade de tempo para sua elaboração, uma vez que o planejamento faz-se necessário com perspectivas de sucesso da atividade e no cotidiano do trabalho do enfermeiro da unidade de internação, nem sempre isto é possível, pois o mesmo realiza atividades de assistência direta e indireta sendo apenas um enfermeiro por plantão. Assim, estratégias que favoreçam a prevenção de acidentes com pérfurocortantes e fluidos corporais e do trabalho, de um modo geral, devem fazer parte da política institucional.

\section{CONSIDERAÇÕES FINAIS}

Com o relato de experiência esperamos estimular o profissional de enfermagem a refletir sobre a importância da prevenção, notificação e compreensão das fases percorridas pelo profissional exposto a risco de acidentes com pérfuro-cortantes e fluidos orgânicos, com vistas a contribuir para o enriquecimento de conhecimento sobre o tema e minimizar a ansiedade causada pelo acidente no local de trabalho.

O desenvolvimento do diagnóstico situacional durante a disciplina Estágio Supervisionado II: área hospitalar pôde demonstrar que as inquietações no campo da prática podem resultar em intervenções exeqüíveis e condizentes com a necessidade local, 
aproximando o conhecimento tácito e explícito, levando o profissional a buscar resolução de problemas reais ou potenciais.

A atividade desenvolvida promoveu estreitamento do relacionamento entre a discente, as docentes e os profissionais de enfermagem do setor, bem como o envolvimento de outros serviços da instituição, favorecendo a comunicação e a troca de experiências, num esforço conjunto para enfrentamento do problema aqui abordado.

Ao finalizar esse relato, ressalta-se que cabe ao enfermeiro buscar informações e desenvolver ações voltadas à metodologia de educação em serviço, promovendo o envolvimento da equipe de enfermagem, a exemplo da atividade desenvolvida, voltada a consolidar ações quanto à prevenção de acidentes com pérfuro-cortantes e fluidos orgânicos, exercitando as habilidades teórico-práticas adquiridas durante a sua formação profissional, iniciada pela formação acadêmica.

\section{REFERÊNCIAS}

1. Oliveira MP de, Soares CR. Acidentes ocupacionais com material pérfuro-cortante e fluidos orgânicos In: Schechter M, Mirangoni DV. Doenças infecciosasconduta, diagnóstico e terapêutica. Rio de Janeiro: Guanabara Koogan; 2003 p.87-95.

2. Nichiata LYI, Gir E, Takahashi RF, Ciosak SI. Evolução dos isolamentos em doenças transmissíveis: os saberes na prática contemporânea. Rev Esc Enferm USP. 2004; 38(1):61-70.

3. Marziale MHP, Rodrigues CM. A produção cientifica sobre os acidentes de trabalho com material pérfurocortante entre trabalhadores de enfermagem. Rev Latino-Am Enferm. 2002 Jul-Ago;10(4):571-7.

4. Brunner LS, Suddarth DS. Tratado de enfermagem médico-cirúrgica. $10^{\mathrm{a}}$ ed. Rio de Janeiro: Guanabara Koogan; 2006.

5. Cavalcante NJF, Pereira NA. Saúde ocupacional. In: Fernandes AT, Fernandes MOV, Filho NR. Infecção hospitalar e suas interfaces na área da saúde. São Paulo: Atheneu; 2000.p.1287-99.

6. Oliveira AC. Infecções hospitalares: Epidemiologia, prevenção e controle. Rio de Janeiro: Guanabara e Koogan; 2005.

7. Minas Gerais. Coordenadoria Estadual de DST/AIDS.
Cartilha saiba como se proteger: doenças sexualmente transmissíveis: Belo Horizonte; 2005.

8. Séqueira EJD. Saúde ocupacional e medidas de biossegurança. In: Martins MA. Manual de infecção hospitalar: prevenção e controle. Rio de Janeiro: MEDSI; 2001. 